\title{
The prevalence of depression in rheumatoid arthritis in China: A systematic review
}

\author{
Xin Fu ${ }^{1, *}$, Zhi-Jun $\mathrm{Li}^{2,}{ }^{*}$, Chun-Jun Yang ${ }^{3}$, Liangshu Feng ${ }^{4}$, Lemeng Sun ${ }^{5}$, Yang Yao \\ and Yu-Ting Huang ${ }^{7}$ \\ ${ }^{1}$ Department of Orthopaedics, Tianjin Hospital, Tianjin, China \\ ${ }^{2}$ Department of Orthopaedics, Tianjin Medical University General Hospital, Tianjin, China \\ ${ }^{3}$ Department of Nursing, Tianjin Medical University General Hospital, Tianjin, China \\ ${ }^{4}$ Department of Neurology and Neuroscience Center, First Hospital of Jilin University, Changchun, China \\ ${ }^{5}$ Cancer Center, First Hospital of Jilin University, Changchun, China \\ ${ }^{6}$ Department of Neurology, Tianjin Medical University General Hospital, Tianjin, China \\ ${ }^{7}$ Children's Research Institute, Children's National Medical Center, Washington, DC, USA \\ *These authors have contributed equally to this work \\ Correspondence to: Yu-Ting Huang, email: hyacinth0256228@hotmail.com \\ Yang Yao, email: yy1986@stanford.edu \\ Keywords: depression, rheumatoid arthritis, prevalence, meta-analysis
}

Received: January 23, $2017 \quad$ Accepted: March 20, $2017 \quad$ Published: April 21, 2017

Copyright: Fu et al. This is an open-access article distributed under the terms of the Creative Commons Attribution License 3.0 (CC BY 3.0), which permits unrestricted use, distribution, and reproduction in any medium, provided the original author and source are credited.

\section{ABSTRACT}

This systematic review is to explore the prevalence of depression in patients with rheumatoid arthritis (RA) in China. Articles of prevalence rates for depression in adult RA patients published before October 2015 were identified from PubMed, Embase, The Cochrane Library, CNKI, CBM, VIP, and Wanfang database and other internet databases. Relevant journals and the recommendations of expert panels were also searched manually. Two independent reviewers searched and assessed the literature. Therelevant data were applied with Meta-Analyst 3.13 software, and the forest plot and funnel plot were performed. 21 studies with a total of 4447 patients were selected to be enrolled in this study. The prevalence of depression by analyzing the effect size was $48 \%$ [ $95 \%$ CI $(41 \%, 56 \%)$ ]. The prevalence of minor depression and dysthymic disorder was 30\% [95\%CI (23\%, 38\%)], and the moderate or major depression was $18 \%$ [95\%CI $(11 \%, 29 \%)]$, respectively. Subgroup analysis showed that the depression rate of female RA patients was higher than male. The depression rate in the central and western areas were higher than that of the eastern region of China, the prevalence level estimated by the Geriatric Depression Scale (GDS) was higher than estimated by other tools. Sensitivity analysis showed that the pooled effect size had good stability and reliability, To be conclusive, the prevalence rate of depression in RA patients is $\mathbf{4 8} \%$, which suggesting that medical staff should pay more attention to depression in adult patients with RA.

Level of evidence III

Rheumatoid arthritis (RA) is a chronic disease with an unknown etiology, presenting as systemic inflammatory autoimmune diseases, characterized by joint pain, swelling, stiffness, and deformation. At the early stage, RA symptoms mainly include fatigue, lack of appetite, low-grade fever, and joint aches; at the late stage, the symptoms of joint, including stiffness, deformity, and even loss of function. These clinical manifestations may subsequently lead to psychological distress [1]. Depression is highly prevalent in individuals with RA, with some studies reporting that the prevalence rates of depression are up to $41.5 \%$ [2], higher than the general population [3], even higher than 
those patients with diabetes [4], Parkinson [5], and cancer [6]. Depression in RA is associated with increasing pain [7], fatigue [8], physical disability [9], co-morbidities, health service utilization [10], mortality [11], suicide risk [12], and healthcare costs [13]; decreased in quality of life [14], treatment compliance, and work productivity [15].

Nearly $1 \%$ of the populations throughout the developed countries are affected by RA [10]. Previous studies have attempted to use some data to examine the strength of the associations between depression and RA. Different studies on RA patients with depression in China reported the prevalence estimates for depression range greatly from $8 \%$ to $78 \%$ [16-33]. The wide range in the prevalence of depression in the clinical studies of RA is likely due to the difference of study quality, variations in definitions of depression, and the methods used for measuring the depressive symptoms. Matcham et al. had provided pooled prevalence rates of depression in patients with RA in the world range [34]. However, according to the difference of religious belief, geographic distribution and socio-economic status in China, the prevalence estimates for depression is different comparing with the results in other countries. Despite, the importance of depression with RA patients, the aim of developing this systematic review study by performing a metaanalysis of the available data from previous studies is to comprehensively investigate pooled prevalence estimates of RA patients with depression in China.

\section{RESULTS}

\section{Literature search results}

The search yielded 1443 journal articles, all duplicate articles were removed. 554 potentially eligible studies subjected to further screening.By reading the title and abstract, 517 studies did not meet our selection criteria. After review of the full text, 16 articles were ruled out. Finally, 21 studies were included with a total of 4447 individuals in the analysis (Figure 1).

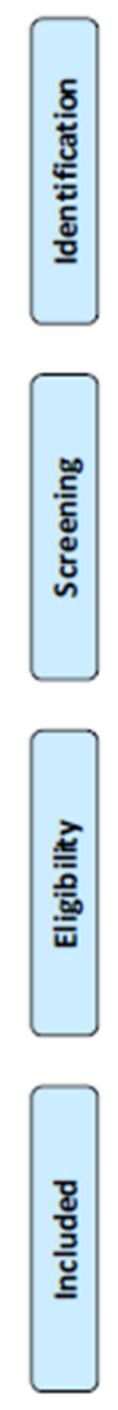

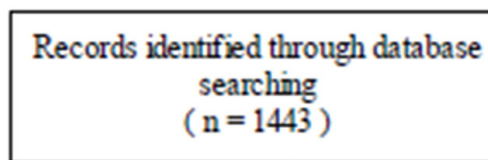

$(\mathrm{n}=1443$ )

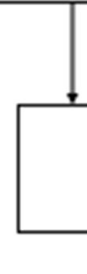

Records after duplicates removed

$(\mathrm{n}=889$ )

\section{Additional records identified through other sources $(\mathrm{n}=0)$}

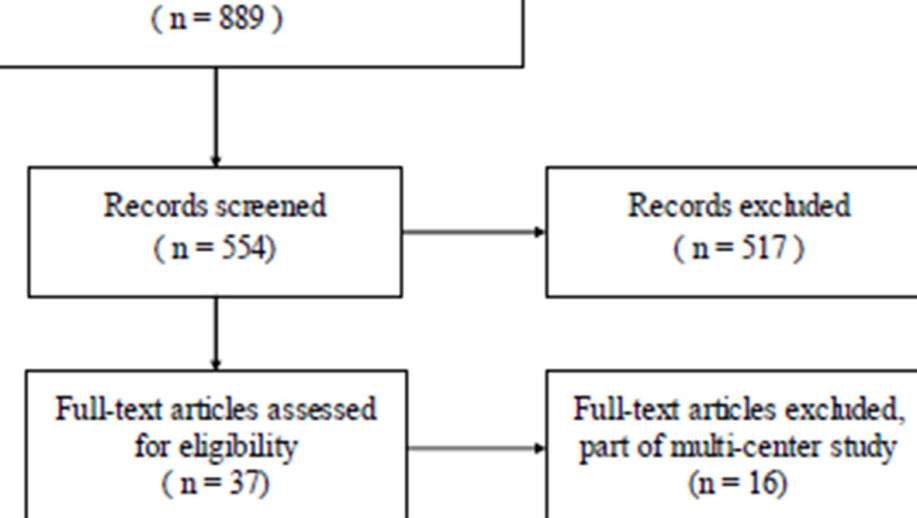

Figure 1: Flow diagram of the literature search and selection process. 
Table 1: Summary of clinical studies characteristics and prevalence rates for depression in RA patients

\begin{tabular}{lcccccccc}
\hline Study & Duration & Province & Sample size & No. of A & Prevalence & No. of B & No. of C & Tools \\
\hline Wu XM & $2002-2004$ & Jiangsu & 86 & 63 & $73 \%$ & NS & NS & SDS \\
Li H & 2010 & Anhui & 173 & 127 & $73.4 \%$ & 76 & 51 & SDS \\
Yao XM & $2008-2010$ & Guizhou & 258 & 181 & $70.16 \%$ & 89 & 92 & SDS \\
Li CF & 2008 & Henan & 40 & 12 & $30 \%$ & NS & NS & SDS \\
Ru HY & $2010-2011$ & Guangdong & 38 & 10 & $26.3 \%$ & NS & NS & SDS \\
Yin PH & $2000-2001$ & Beijing & 30 & 22 & $73.3 \%$ & 11 & 11 & NS \\
Wu M & $2009-2010$ & Guangdong & 160 & 125 & $78.1 \%$ & 67 & NS & NS \\
Dong LX & $2011-2012$ & Hunan & 169 & 64 & $37.8 \%$ & NS & NS & SDS \\
Wang YG & 2010 & Guangdong & 150 & 12 & $8 \%$ & 8 & 3 & SDS \\
Yin GF & $2009-2010$ & Shangdong & 160 & 56 & $35 \%$ & 33 & 19 & HAMD \\
Huang JL & $2004-2005$ & Guangdong & 60 & 18 & $30 \%$ & NS & NS & SDS \\
Liu J & $2005-2006$ & Anhui & 136 & 84 & $61.76 \%$ & NS & NS & SDS \\
Zheng ZJ & $2006-2007$ & Anhui & 100 & 53 & $53 \%$ & 39 & 11 & SDS \\
Guo JB & $2011-2012$ & Hebei & 2156 & 1433 & $66.5 \%$ & NS & NS & SDS \\
Zhang H & $2008-2009$ & Hubei & 86 & 35 & $34.9 \%$ & NS & NS & NS \\
Li QP & 2004 & NS & 58 & 27 & $27.6 \%$ & 16 & NS & SDS \\
Wang Y & $2009-2011$ & Shangxi & 201 & 87 & $43.3 \%$ & NS & NS & SDS \\
Chen X & $2007-2011$ & Beijing & 112 & 62 & $55.4 \%$ & 38 & 15 & HAMD \\
Chen Q & $2007-2010$ & Sichuan & 125 & 49 & $39.2 \%$ & NS & NS & SDS \\
Jiang LD & $1997-1998$ & Shanghai & 95 & 41 & $43.2 \%$ & NS & NS & SDS \\
Wang JL & $2005-2006$ & Hebei & 54 & 19 & $35.2 \%$ & NS & NS & SDS \\
\hline
\end{tabular}

NS: no stated; A: patients with depression; B: patients with mild depression; C: patients with moderate or severe depression; SAS: Self-Rating Depression Scale; HAMD: Hamilton depression Rating Scale.

\section{Study characteristics}

Twenty-one studies with a total of 4447 individuals were included in the analysis. The characteristics of included studies are summarized in Table 1. 2580 individuals were reported as RA patients with depression. The median number of participants per-study was 212 , ranging from 30 to 2156 . To further characterize the range of depression or depressive symptom prevalence estimates identified by these methodologically diverse studies, three studies [18$19,28]$ did not mention the method sused to identify patients with depression, two studies $[22,31]$ used the Hamilton Depression Scale (HAMD) to identified, and the remaining 16 studies were using the Self-rating Depression Scale (SDS) to evaluate. Nine studies [18$19,22,26,29,31,35-36]$ have demonstrated the rate of major depression and minor depression and dysthymic disorder, including 337 individuals with minor depression and dysthymic disorder, and 279 individuals with major depression.

\section{Quality assessment}

According to the quality assessment tool (JBI standard), the overall quality of all 21 articles was generally good.Eighteen studies [16-20, 23-32, 35-37] scored $14 / 20$ or higher, and four articles $[19,21-22$, 33] scored $13 / 20$ due to not describing in detail the method of random sampling, the inclusion and exclusion criteria, sample characteristics, and the lack of checking information.

\section{Results of the meta-analysis}

\section{Prevalence of depression}

The meta-analytical pooled prevalence of depression (Figure 2) according to the diagnostic 
criteria of HAMD or SDS was 48\% [95\% CI (41\%, $56 \%)$ ] with moderate heterogeneity $\left(\mathrm{I}^{2}=94.8 \%\right)$. The results of publication bias showed in (Supplementary Figure 1). Visual inspection of the funnel plot of studies reporting on depression or depressive symptoms revealed significant asymmetry, which indicating possible publication bias.
Prevalence of minor depression and dysthymic disorder

Nine articles evaluate the prevalence of minor depression and dysthymic disorder by diagnostic criteria of SDS, the analysis indicating a pooled prevalence level of $30 \%$ [95\% CI $(23 \%, 38 \%)]$, with moderate heterogeneity $\left(\mathrm{I}^{2}=87.4 \%\right)$ (Figure 3$)$. Visual inspection

\begin{tabular}{|c|c|c|c|c|c|c|c|}
\hline Study & Events & Total & & Proportion & $95 \%-\mathrm{Cl}$ & $W($ fixed) & $\mathrm{W}$ (random) \\
\hline Wu XM & 63 & 86 & $\longrightarrow$ & 0.73 & {$[0.63 ; 0.82]$} & $1.7 \%$ & $4.7 \%$ \\
\hline $\mathrm{LiH}$ & 127 & 173 & $\longrightarrow$ & 0.73 & {$[0.66 ; 0.80]$} & $3.5 \%$ & $5.0 \%$ \\
\hline Yao XM & 181 & 258 & $\div$ & 0.70 & {$[0.64 ; 0.76]$} & $5.6 \%$ & $5.1 \%$ \\
\hline Li CF & 12 & 40 & & 0.30 & {$[0.17 ; 0.47]$} & $0.9 \%$ & $4.3 \%$ \\
\hline Ru HY & 10 & 38 & & 0.26 & {$[0.13 ; 0.43]$} & $0.8 \%$ & $4.2 \%$ \\
\hline Yin $\mathrm{PH}$ & 22 & 30 & & 0.73 & {$[0.54 ; 0.88]$} & $0.6 \%$ & $3.9 \%$ \\
\hline Wu M & 125 & 160 & $\longrightarrow$ & 0.78 & {$[0.71 ; 0.84]$} & $2.8 \%$ & $4.9 \%$ \\
\hline Dong LX & 64 & 169 & & 0.38 & {$[0.31 ; 0.46]$} & $4.1 \%$ & $5.0 \%$ \\
\hline Wang YG & 12 & $150 \div$ & & 0.08 & {$[0.04 ; 0.14]$} & $1.1 \%$ & $4.5 \%$ \\
\hline Yin GF & 56 & 160 & & 0.35 & {$[0.28 ; 0.43]$} & $3.8 \%$ & $5.0 \%$ \\
\hline Huang JL & 18 & 60 & & 0.30 & {$[0.19 ; 0.43]$} & $1.3 \%$ & $4.6 \%$ \\
\hline Liu J & 84 & 136 & & 0.62 & {$[0.53 ; 0.70]$} & $3.3 \%$ & $5.0 \%$ \\
\hline Zheng ZJ & 53 & 100 & & 0.53 & {$[0.43 ; 0.63]$} & $2.6 \%$ & $4.9 \%$ \\
\hline Guo JB & 1433 & 2156 & + & 0.66 & {$[0.64 ; 0.68]$} & $49.6 \%$ & $5.2 \%$ \\
\hline Zhang H & 35 & 86 & & 0.41 & {$[0.30 ; 0.52]$} & $2.1 \%$ & $4.8 \%$ \\
\hline Li QP & 27 & 58 & 1 & 0.47 & {$[0.33 ; 0.60]$} & $1.5 \%$ & $4.6 \%$ \\
\hline Wang $Y$ & 87 & 201 & & 0.43 & {$[0.36 ; 0.50]$} & $5.1 \%$ & $5.1 \%$ \\
\hline Chen X & 62 & 112 & & 0.55 & {$[0.46 ; 0.65]$} & $2.9 \%$ & $4.9 \%$ \\
\hline Chen Q & 49 & 125 & & 0.39 & {$[0.31 ; 0.48]$} & $3.1 \%$ & $4.9 \%$ \\
\hline Jiang LD & 41 & 95 & & 0.43 & {$[0.33 ; 0.54]$} & $2.4 \%$ & $4.9 \%$ \\
\hline Wang JL & 19 & 54 & & 0.35 & {$[0.23 ; 0.49]$} & $1.3 \%$ & $4.5 \%$ \\
\hline Fixed eff & & 4447 & $\hat{\beta}$ & 0.59 & {$[0.57 ; 0.60]$} & $100 \%$ & \\
\hline Random & & & & 0.48 & {$[0.41 ; 0.56]$} & -- & $100 \%$ \\
\hline \multicolumn{3}{|c|}{$\begin{array}{l}\text { Random efrects model } \\
\text { Heterogeneity: } 1 \text {-squared }=94.8 \% \text {, tau-squared }=0.5083, \rho<0.0001\end{array}$} & & & & & \\
\hline & & 0.2 & 0.8 & & & & \\
\hline
\end{tabular}

Figure 2: Meta-analysis of the prevalence rates for depression in RA patients in China.

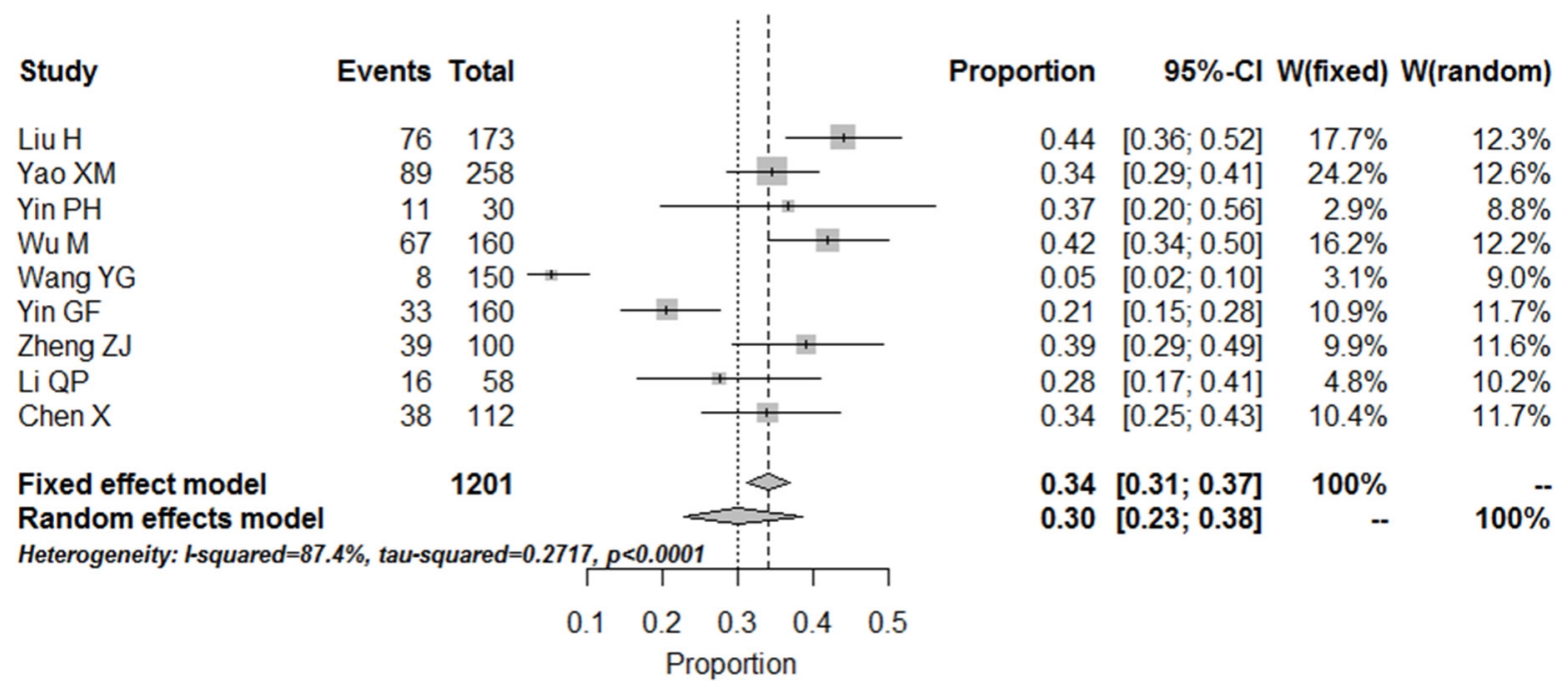

Figure 3: Meta-analysis of the prevalence rates for minor depression in RA patients in China. 
of the funnel plot of studies suggested possible publication bias (Supplementary Figure 2).

\section{Prevalence of major depression}

Nine articles also evaluate the prevalence of major depression according to the SDS, indicating a pooled prevalence level of $18 \%$ [95\% CI (11\%, 29\%)] (Figure 4). Visual inspection of the funnel plot of studies reporting on depression or depressive symptoms revealed significant asymmetry, which indicating possible publication bias (Supplementary Figure 3).

\section{Sensitivity analysis and subgroup analysis}

After removing two studies using HAMD (as diagnostic criteria) to identified the level of depression, pooled effects size is $49 \%$ [95\%CI $(40 \%, 57 \%)]$. The results of sensitivity analysis showed that the main effect size was of stability and reliability. The subgroup analyses were conducted according to sample size, overall quality and publication year. The subgroup analysis showed that the depression rate of female RA patients was higher than male. The depression rate in the central and western areas was higher than that of the eastern region of China, the prevalence level estimated by the GDS was higher than estimated by other tools, However, more recent publications tended to yield higher prevalence estimates.

\section{DISCUSSION}

Depression is highly prevalent in RA patients. Estimates varied according to the way in which depression was measured, but this study used the Meta-Analyst 3.13 software to measure the prevalence of depression in RA patients in China, which the result suggests that the depressive symptoms present in $48 \%$ [95\% CI (41\%, $56 \%$ )] in China, closing to the median $41.2 \%$ in all 21 studies. The minor depression and dysthymic disorder is present in $30 \%$ [95\% CI $(23 \%, 38 \%)]$ and moderate to major depression is present in 18\% [95\% CI (11\%, 29\%)]. One previous meta-analysis published in 2013 showed that significant depressive symptoms presented in $38.8 \%$ using the PHQ-9 and between $14.8 \%$ and $48 \%$ using the HADS [38]. Compared with the results of this study, the prevalence estimates for depression is higher in our study. The cause of this difference is likely to depend on religious belief, geographic distribution and socio-economic status, which need to be explored further.

The results of the prevalence rates of depression in RA differ significantly between China and other countries, mainly for the following reasons: firstly, most self-rating scales are chosen as the assessment tools for depression because they are cheaper and can be completed quickly, which could probably be influenced by subjective factors of patients. Secondly, it is likely to produce inaccurate results due to the lack of sample size or high-quality studies;finally, a diversity of studies varied widely in terms of the baseline, such as the age proportion, complication, can be considered as interference factors [39].

Various assessment questionnaires were used to measure the level of depression, such as the Patient Health Questionnaire (PHQ) [40], the Hospital Anxiety and Depression Scale (HADS) [41], Beck depression inventory (BDI) [42], Self-Rating Depression Scale (SDS) [43] and GDS [44]. However, the screening questionnaire of Hamilton Depression Rating Scale (HAMD) and SDS are the most commonly used in China. In this systematic review, all studies used SDS or HAMD to ascertain the level of depression. As a self-report screening tool, SDS is commonly used to assess the level of depression of patients, and its reliability and validity have been examined in China [45]. It includes 20 items, with each subscale rated on a fourpoint scale and scored from 1 to 4 (never or occasionally,

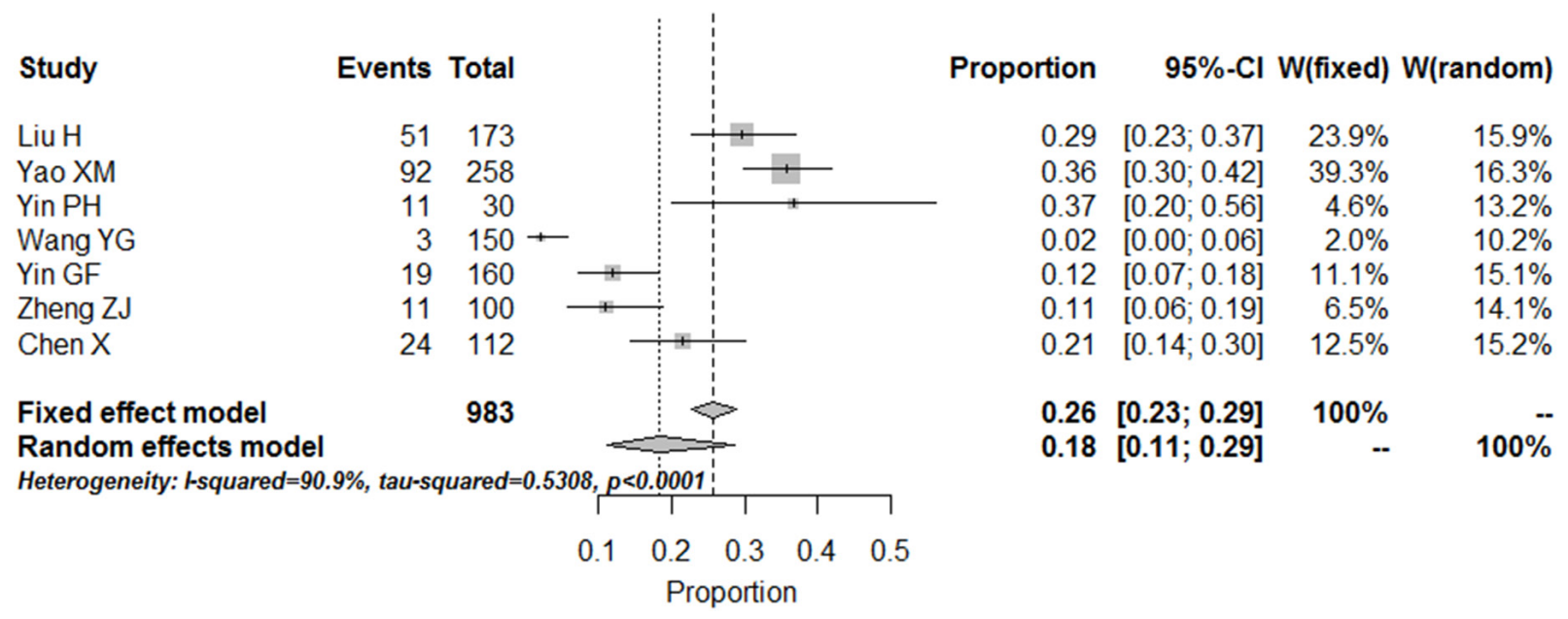

Figure 4: Meta-analysis of the prevalence rates for moderate and major depression in RA patients in China. 
sometimes, often and most of the time). Total scores are calculated by summing the items on each subscale, and the standardized score is the total score times 1.25 , a total standard score of 53 was set as a cut-off point of depression. Scores between 53 and 62 represent minor depression and dysthymic disorder; 63 to 72 suggest 'moderate depression' and above 72 indicate 'major depression' [46-47]. HAMD is a validated method for measuring the level of depression. It consists of 24 items, in which 14 items is scored from 0 to 4 and 10 items is scored from 0 to 2 , resulting in a total score of 0 to 76 . According to the classification criterion: the level of depression is divided into no depression (0-7); minor or moderate depression (20-34); major depression (above 35) [48]. Therefore, different screening tools have different cut-point to assess the level of depression, and prevalence estimates are often relying on predefined thresholds, therefore, the prevalence rates of depression according to these different tools may be inaccurate. In this review, the pooled effects size is $48 \%$ [ $95 \% \mathrm{CI}(41 \%, 56 \%)$ ] after removing two studies using HAMD, indicating that the main effect size was of stability. The high rates of depressive symptomatology detected through the screening tools could be due to the overlap between the somatic symptoms of depression and symptoms of RA. Symptoms frequently associated with depression (such as fatigue and reduced sleep quality) may be experienced by RA patients regardless of whether depressive symptoms are present or not.

According to sensitivity analysis and publication bias, the results of this study showed that the prevalence estimates of depression were stable, significant publication bias is presented in the prevalence estimates for minor and major depression because of insufficient sample size. More high-quality researches are needed in the future.

There are some limitations in this study, which needed to be addressed: firstly, the data were derived from studies that had different designs, screening instruments, and trainee demographics. The substantial heterogeneity among the studies remained largely unexplained by the variables inspected. Secondly, because the studies were heterogeneous with respect to screening inventories and populations, the prevalence of major depression could not be determined. Finally, many subgroup analyses relied on unpaired crosssectional data collected at different medical centers, which may cause confounding.

\section{CONCLUSION}

The result of this meta-analysis is almost consistent with national epidemiological survey of RA patients in China, indicating the result is reliable, which provides key parameter for making strategies to care for the patients with rheumatoid arthritis. Furthermore, efforts are continually needed to reduce barriers to mental health services, including addressing the stigma of depression.

\section{MATERIALS AND METHODS}

\section{Search strategy}

For our systematic review, we looked at all English and non-English academic articles identified from different electronic databases, including MEDLINE, EMBASE, Chinese journal full-text database (CNKI), Chinese biomedical database (CBM), Chinese science and technology periodical database, and Wanfang database. The search strategy is presented in Figure 1. In addition, the Google scholar search engine was searched manually using the same search terms to seek further relevant studies that may have been missed in the database search. We used the keywords 'Rheumatoid arthritis' and 'depression' and 'China'. Broad MeSH terms and Boolean operators were selected for each database search. The literature search was updated on October 2015. The reference lists of all the fulltext papers were examined to identify any initially omitted studies. We made no restrictions on the language of the publications [38].

\section{Data extraction and quality assessment}

The selection criteria used to evaluate the association between rheumatoid arthritis and depression, each article using a standardized form: the age of RA patientsis above 18, reported a prevalence level or incidence of depression in RA patients, the sample size was more than 30 , the cross-sectional observational study, baseline data including the level of depression.

For each eligible study, two of the reviewers (Li Z.J. and $\mathrm{Fu} \mathrm{X}$.) extracted all the relevant data independently. Any disagreement was resolved by discussion when no consensus could be achieved, the third reviewer (Huang Y.T.) was the adjudicator and made the final decision. Whenever necessary, we contacted the authors of the studies for the missing data or further information. The following data were extracted: the secondary sources including the review, the error in research design or statistical method, studies in special population, such as pregnant women with RA, children with RA. We assessed trial quality using the JBI (Joanna Briggs Institution) critical appraisal score that is reliable. The quality assessment tool consists of a total of 10 items with each item scored from 0 to 20 . Total scores are calculated by summing the items on each subscale, and the article was regarded as good quality if the score was above 14 [49].

\section{Outcome measures}

Outcomes were divided into mild, moderate or major depression according to the screening tool of Hamilton depression scale (HADS) or self-rating depression scale (SDS). 


\section{Statistical analysis}

The Meta-Analyst 3.13 software was used to undertaken meta-analysis. The ratio and $95 \%$ confidence interval (CI) from each study were calculated. The heterogeneity was assessed using $\mathrm{I}^{2}$, an $\mathrm{I}^{2}$ value of $50 \%$ was considered to indicate substantial heterogeneity. The origins of heterogeneity, if present, were analyzed according to differences in methodological quality and the characteristics of the participants. Heterogeneity was found to be moderately high between studies, and therefore random effects meta-analyses with $95 \%$ CIs were conducted [50-51]. When the data allowed, the authors of this paper performed subgroup analysis and sensitivity analyses. Funnel plots were produced to explore the possibility of publication bias.

\section{ACKNOWLEDGMENTS}

This work was supported by funding from National Natural Science Foundation of China (No. 81501887 and 81502247) and Youth Program of Tianjin Nature Science Foundation (No. 14JCQNJC11700 and 14JCQNJC14100). The funders had no role in the design, execution, and writing up of the study.

\section{CONFLICTS OF INTEREST} interest.

All authors state that they have no conflicts of

\section{REFERENCES}

1. Gettings L. Psychological well-being in rheumatoid arthritis: a review of the literature. Musculoskeletal Care. 2010; 8:99-106.

2. Gao L, Zhang XC, Li MM, Yuan JQ, Cui XJ, Shi BX. Psychometric properties of the Chinese version of Arthritis Self-Efficacy Scale-8 (ASES-8) in a rheumatoid arthritis population. Rheumatol Int. 2017; 37:751-6.

3. Waraich P, Goldner EM, Somers JM, Hsu L. Prevalence and incidence studies of mood disorders: a systematic review of the literature. Can J Psychiatry. 2004; 49:124-38.

4. Roy T, Lloyd CE. Epidemiology of depression and diabetes: a systematic review. J Affect Disord. 2012; 142:S8-21.

5. Reijnders JS, Ehrt U, Weber WE, Aarsland D, Leentjens AF. A systematic review of prevalence studies of depression in Parkinson's disease. Mov Disord. 2008; 23:183-9.

6. Mitchell AJ, Chan M, Bhatti H, Halton M, Grassi L, Johansen C, Meader N. Prevalence of depression, anxiety, and adjustment disorder in oncological, haematological, and palliative-care settings: a meta-analysis of 94 interviewbased studies. Lancet Oncol. 2011; 12:160-74.

7. Koop SM, ten Klooster PM, Vonkeman HE, Steunebrink LM, van de Laar MA. Neuropathic-like pain features and cross-sectional associations in rheumatoid arthritis. Arthritis Res Ther. 2015; 17:237.

8. van Hoogmoed D, Fransen J, Bleijenberg G, van Riel P. Physical and psychosocial correlates of severe fatigue in rheumatoid arthritis. Rheumatology (Oxford). 2010; 49:1294-302.

9. el-Miedany $\mathrm{YM}$, el-Rasheed $\mathrm{AH}$. Is anxiety a more common disorder than depression in rheumatoid arthritis? Joint Bone Spine. 2002; 69:300-6.

10. Scott DL, Wolfe F, Huizinga TW. Rheumatoid arthritis. Lancet. 2010; 376:1094-108.

11. Ang DC, Choi H, Kroenke K, Wolfe F. Comorbid depression is an independent risk factor for mortality in patients with rheumatoid arthritis. J Rheumatol. 2005; 32:1013-9.

12. Timonen M, Viilo K, Hakko H, Särkioja T, Ylikulju M, Meyer-Rochow VB, Väisänen E, Räsänen P. Suicides in persons suffering from rheumatoid arthritis. Rheumatology (Oxford). 2003; 42:287-91.

13. Joyce AT, Smith P, Khandker R, Melin JM, Singh A. Hidden cost of rheumatoid arthritis (RA): estimating cost of comorbid cardiovascular disease and depression among patients with RA. J Rheumatol. 2009; 36:743-52.

14. Kopciuch D, Paczkowska A, Leszczynsk P, Michalak M, Nowakowskai E. Effect of therapy with anti-TNF alpha drugs and DMARD on disease activity and health related quality of life among women with rheumatoid arthritis. Acta Pol Pharm. 2016; 73:547-54.

15. Li X, Gignac MA, Anis AH. The indirect costs of arthritis resulting from unemployment, reduced performance, and occupational changes while at work. Med Care. 2006; 44:304-10.

16. Li CF, Xing H. The psychological analysis and nursing for elderly patients withrheumatoid arthritis. J Belhune Mil Med Coll. 2008; 6:246-247.

17. Ru HY, Feng M, Chen ZR. The investigation and nursing of psychological condition in elderly patients with rheumatoid arthritis. J Qilu Nurs. 2013; 19:66-7.

18. Yin PH, Ji YD, Wang J. The investigation and nursing of depression in elderly patients with rheumatoid arthritis. Chinese J Nurs. 2002; 37:456-8.

19. $\mathrm{Wu} \mathrm{M}$. The investigation and nursing intervention of depression in elderly patients with rheumatoid arthritis. Nurs Pract Res. 2011; 8:124-5.

20. Dong LX, Li LJ, You M, Shao P. Depression of patients with rheumatoid arthritis(RA) and comprehensive intervention. China J Health Psychol. 2013; 21:348-50.

21. Wang YG, Zhang LJ, Shu B, Cao L, Liu Y. Psychological state of 150 patients with rheumatoid arthritis. Occup Health. 2011; 27:cover2- 3.

22. Yin GF, Yue M, Nie JP, Liu FH, Zhou J. The clinical investigation of rheumatoid arthritis patients with depression. Shandong J Tradit Chinese Med. 2011; 3:703-4. 
23. Huang JL, Zeng YM, Xiao XQ. The investigation of rheumatoid arthritis patients with depression and anxiety. $\mathrm{J}$ Med Theory Pract. 2005; 18:1355-6.

24. Liu J, Yang MY, Fan HX. Correlation analysis between anxiety and depression and quality of life in patients with rheumatoid arthritis. Chinese J Rehabil. 2007; 22:11-3.

25. Zheng ZJ. The correlation between anxiety and depression and quality of life in patients with rheumatoid arthritis. Chinese J Clin Healthcare. 2010; 13:9-11.

26. Guo JB, Li L, Yang JL. Investigation and analysis of anxiety and depression of patients with rheumatoid arthritis. Rheum Arthritis. 2012; 1:28-9.

27. Zhang $\mathrm{H}$. The correlation between pain and depression in patients with rheumatoid arthritis. Guangdong Med J. 2010; 31:2922-3

28. Li QP. Investigation on anxiety, depressive mood and relative factors of patients with rheumatoid arthritis. Mod Nurs. 2005; 11:1685-7.

29. Wang Y, Wang XR. The investigation and analysis of rheumatoid arthritis patients with depression. Guide China Med. 2011; 9:354-6.

30. Chen X, Yang M, Wang T. Analysis on depression and the related factors in patients with rheumatoid arthritis. Chinese J Clin. (Electron Ed.). 2013; 7:2809-2812.

31. Chen Q. Depression in rheumatoid arthritis. China Health Ind. $2011 ; 8: 26-8$.

32. Jiang LD, Ji JL, Wang JY. The investigation of rheumatoid arthritis patients with depression. Chinese J Rheumatol. 1999; 3:169-71.

33. Wang JL, Tian YN, Ning XR, Zhang FX, Tao JM. The investigation of rheumatoid arthritis patients with depression and anxiety. Chinese J Difficult and Complication Cases. 2006; 5:287-8.

34. Kawada T. The prevalence of depression in rheumatoid arthritis: a systematic review and meta-analysis. Rheumatology (Oxford). 2014; 53:578.

35. Liu H, Zhou ZQ. Analysis on relationship between depression and cognitive tendencies in patients with rheumatic diseases. Chinese Nurs Res. 2012; 26: 2345-6.

36. Yao, XM, Ma W, Tang F, Huang Y. Analysis of depression in rheumatoid arthritis patients from Guiyang citizens. J Guangzhou Univ Tradit Chinese Med. 2011; 28:222-225.

37. Wu XM, Xing JF, Zuo YJ. The investigation and analysis of depression in common type of rheumatoid disease. J Qiqihar Med Coll. 2005; 26:1264-5.

38. Matcham F, Rayner L, Steer S, Hotopf M. The prevalence of depression in rheumatoid arthritis: a systematic review and meta-analysis. Rheumatology (Oxford). 2013; 52:2136-48.

39. Goodenow C, Reisine ST, Grady KE. Quality of social support and associated social and psychological functioning in women with rheumatoid arthritis. Health Psychol. 1990; 9:266-84.
40. Lora A, Hanna F, Chisholm D. Mental health service availability and delivery at the global level: an analysis by countries' income level from WHO's Mental Health Atlas 2014. Epidemiol Psychiatr Sci. 2017; 13:1-12.

41. Muscatello MR, Troili GM, Pandolfo G, Mento C, Gallo G, Lanza G, Pintaudi B, Di Vieste G, Di Benedetto A, Zoccali RA, Bruno A. [Depression, anxiety and anger in patients with type 1 diabetes mellitus]. [Article in Italian]. Recenti Prog Med. 2017; 108:77-82.

42. Worsley R, Bell RJ, Gartoulla P, Robinson PJ, Davis SR. Moderate-severe vasomotor symptoms are associated with moderate-severe depressive symptoms. J Womens Health (Larchmt). 2017; 26:712-18. doi: 10.1089/jwh.2016.6142.

43. Huang C, Momma H, Cui Y, Chujo M, Otomo A, Sugiyama S, Ren Z, Niu K, Nagatomi R. Independent and combined relationship of habitual unhealthy eating behaviors with depressive symptoms: a prospective study. J Epidemiol. 2017; 27:42-7.

44. Foscolou A, Tyrovolas S, Soulis G, Mariolis A, Piscopo S, Valacchi G, Anastasiou F, Lionis C, Zeimbekis A, Tur JA, Bountziouka V, Tyrovola D, Gotsis E. The Impact of the financial crisis on lifestyle health determinants among older adults living in the Mediterranean region: the multinational MEDIS study (2005-2015). J Prev Med Public Health. 2017; 50:1-9.

45. Peng Hea. Analysis of reliability and validity of Chinese version SDS Scale in women of rural area. Chinese J Shanghai Med. 2013; 14:20-3.

46. Umegaki Y, Todo N. Psychometric properties of the Japanese CES-D, SDS, and PHQ-9 depression scales in university students. Psychol Assess. 2017; 29:354-9.

47. $\mathrm{Xu} \mathrm{J}$, Wei Y. Social support as a moderator of the relationship between anxiety and depression: an empirical study with adult survivors of Wenchuan earthquake. PLoS One. 2013; 8:e79045.

48. Singh A, Black SE, Herrmann N, Leibovitch FS, Ebert PL, Lawrence J, Szalai JP. Functional and neuroanatomic correlations in poststroke depression: the Sunnybrook Stroke Study. Stroke. 2000; 31:637-44.

49. George PP, DeCastro Molina JA, Heng BH. The methodological quality of systematic reviews comparing intravitreal bevacizumab and alternates for neovascular age related macular degeneration: a systematic review of reviews. Indian J Ophthalmol. 2014; 62:761-7.

50. Li ZJ, Wang Y, Zhang HF, Ma XL, Tian P, Huang Y. Effectiveness of low-level laser on carpal tunnel syndrome: a meta-analysis of previously reported randomized trials. Medicine (Baltimore). 2016; 95:e4424.

51. Li ZJ, Fu X, Tian P, Liu WX, Li YM, Zheng YF, Ma XL, Deng WM. Fibrin sealant before wound closure in total knee arthroplasty reduced blood loss: a metaanalysis. Knee Surg Sports Traumatol Arthrosc. 2015; 23:2019-25. 